\title{
Influência das incertezas nas contratações públicas por intermédio do pregão eletrônico
}

\author{
Angélica Padilha \\ angelicapadilha@utfpr.edu.br \\ Universidade Tecnológica Federal do \\ Paraná, Apucarana, Paraná, Brasil

\section{Everton Coimbra de Araújo} \\ everton@utfpr.edu.br \\ Universidade Tecnológica Federal do \\ Paraná, Medianeira, Paraná, Brasil

\section{José Paulo de Souza} \\ ipsouza@uem.br \\ Universidade Estatural de Maringá, \\ Maringá, Paraná, Brasil
}

\begin{abstract}
RESUMO
Apesar das significativas mudanças trazidas pelo pregão eletrônico, estudos demonstram a recorrência de problemas com as contratações por intermédio da ferramenta, gerando incerteza e custos nas contratações públicas. Neste artigo o objetivo foi identificar as incertezas nas contratações públicas realizadas por intermédio do pregão eletrônico. Tomando como base a abordagem teórica da Economia dos Custos de Transação. A coleta de dados envolveu a pesquisa documental, bibliográfica e a pesquisa de campo em uma Instituição Pública Federal do Paraná. A análise das informações obtidas foi realizada sob o enfoque da análise de conteúdo, complementada pela análise do discurso. A pesquisa evidenciou a presença da incerteza comportamental discutida pela teoria base apresentada. Essa incerteza é fruto da racionalidade limitada dos pregoeiros e requisitantes e do comportamento oportunista dos fornecedores. As evidências da pesquisa associadas à teoria base permitiram concluir que as contratações por intermédio do pregão eletrônico geram custos de transação ex-ante e ex-post para a instituição estudada. Assim, a revisão dos métodos utilizados na descrição dos produtos e serviços e capacitações podem significar caminhos para redução das incertezas do pregão eletrônico e obtenção de maior eficiência para a instituição analisada.
\end{abstract}

PALAVRAS-CHAVE: Compras públicas. Oportunismo. Racionalidade Limitada. 


\section{INTRODUÇÃO}

A reivindicação da sociedade por maior transparência e eficiência nos gastos públicos reflete diretamente nos processos de compras públicas. A busca por alternativas para tornar esses processos mais ágeis, modernos, menos burocráticas, mais transparentes e eficientes, resultou em uma nova modalidade de licitação, o Pregão.

O Pregão, também conhecido como leilão reverso, trouxe para as contratações públicas inovações que o diferencia das demais modalidades. Dentre elas, a possibilidade do uso de recursos de tecnologia da informação para a realização do processo licitatório (FURTADO, 2015). Existem duas formas de pregão: O Pregão Presencial (PP) e o Pregão Eletrônico (PE), ambos disciplinados pela Lei no 10.520/02. No PE, a comunicação entre a Administração e seus fornecedores, e a execução do processo, incluindo a oferta de lances, habilitação, adjudicação e homologação, acontecem por meio da internet.

Para Niebuhr (2015, p. 35) "a eficiência em licitação pública gira em torno de três aspectos fundamentais: preço, qualidade e celeridade". Para o autor, nesse sentido o PE trouxe significativas vantagens, como a economicidade, transparência, redução da burocracia, celeridade, maior participação pelos fornecedores e o aumento da competitividade.

O uso obrigatório do PE pra aquisições federais aumentou o interesse em estudos sobre a ferramenta. Dados do Painel de Compras do Governo Federal (2017) reforçam a importância da gestão eficiente dessa modalidade, uma vez que, em 2016, foram realizados 22.073 pregões, desses 99,59\% eletrônicos, correspondendo a $95,99 \%$ de todas as compras realizadas pela Administração Pública Federal, excluídos processos de dispensa e inexigibilidade.

Alguns estudos sobre o PE já foram realizados. Menezes, Silva e Linhares (2007), por exemplo, propuseram uma Abordagem Multicritério ao pregão eletrônico, onde, além do preço, outros atributos devem ser analisados na tomada de decisão. Faria, Ferreira e Gonçalves (2013) analisaram os riscos do PE, considerando pressupostos da Nova Economia Institucional, classificaram os fornecedores quanto ao grau de risco inerente às contratações.

A eficácia do Pregão Eletrônico no Comprasnet, na eliminação do oportunismo dos licitantes, foi verificada por Oura et al. (2012). Os autores concluíram que embora existam melhoras nas contratações por intermédio do PE, "[...] o uso isolado do PE parece não ser suficiente para coibir ações de oportunismo que, se não podem ser caracterizadas diretamente como fraudes premeditadas, beiram perigosamente esses princípios" (OURA et al. 2012, p. 278).

Apesar dos benefícios trazidos pelo pregão eletrônico, os estudos já apontados indicaram a recorrência de problemas como: qualidade do produto inferior ao desejado pela Administração, quebra contratual por parte do fornecedor, comportamento oportunista, processos desertos, entre outros. Essa recorrência de problemas gera incerteza quanto a eficiência desse processo nas contratações públicas, o que consequentemente gera custos para a Administração. Além disso, a possível elevação nessas ocorrências pode até chegar a inviabilizar o uso da ferramenta. Cabe observar que essas incertezas passam a gerar influência não apenas no momento da execução do pregão, como no seu planejamento, implementação, conclusão, e na entrega do produto ou prestação do serviço 
objeto da contratação.

Diante disso, emerge a necessidade de investigar de que maneira as incertezas estão influenciando na realização do pregão eletrônico por meio do Comprasnet. Além disso, é fundamental conhecer as perspectivas dos pregoeiros e requisitantes dos produtos e serviços com relação às incertezas no PE. Ao identificar essas incertezas, encontrar formas para minimizá-las poderia reduzir os custos associados às contratações por meio do PE?

Teoricamente as incertezas e os custos inerentes à sua gestão podem ser tratados pela Economia dos Custos de Transação (ECT), abordagem advinda da Nova Economia Institucional (NEI). Na ECT, os custos de transação, estão relacionados a dois pressupostos comportamentais: a racionalidade limitada e o oportunismo. Segundo Williamson (1985) enquanto o primeiro se refere aos limites da competência cognitiva humana o segundo refere-se ao auto-interesse com avidez dos indivíduos. Além do aspecto comportamental, na ECT os atributos que diferenciam as transações e norteiam as tomadas de decisões nas contratações, são: a frequência, a incerteza e a especificidade dos ativos. O autor propõe, assim, que o não alinhamento entre os atributos transacionados e as estruturas de governança, que podem ser mercado, integração vertical, e formas intermediárias (híbridas), geram custos de transação, tornando as relações de troca menos eficientes.

Ao se considerar essa orientação teórica identifica-se que a incerteza se apresenta de forma explicita nas aquisições por meio do PE. De um lado pode corresponder à incapacidade de prever todos os eventos, não só ambientais como comportamentais, e de outro pode estar associado às dificuldades de se garantir os direitos no processo de transação. Observa-se, assim, que as transações resultantes do processo de aquisição por meio de pregão eletrônico estão expostas às dificuldades abordadas pela ECT, e, nesse caso, identificá-las e minimizá-las pode resultar em grandes benefícios e ganhos de eficiência, economia, e celeridade para a Administração. Evidenciando a importância de estudos amparados nesse aporte teórico para compreensão dos problemas geradores de sua ineficiência.

Dessa maneira, neste artigo o objetivo foi identificar as incertezas nas contratações públicas realizadas por intermédio do pregão eletrônico. Para tanto, a pesquisa restringiu seu campo de estudo a uma Instituição Pública Federal, localizada no estado do Paraná. A coleta de dados primários incluiu observação sistemática não participante e entrevista semiestruturada com pregoeiros e requisitantes da Instituição. A análise das informações obtidas foi realizada sob o enfoque da análise de conteúdo complementada pela análise de discurso.

Para cumprir o objetivo esse artigo apresenta, além dessa introdução, a sessão dois que discute os pressupostos da ECT e se caracteriza o Pregão Eletrônico e suas fases; a seção três indicando os procedimentos metodológicos utilizados para realização do artigo; a seção quatro indicando os resultados do trabalho de campo; a seção cinco apresenta as considerações finais do trabalho; ao final as referências utilizadas são relacionadas. 


\section{REVISÃO BIBLIOGRÁFICA}

Este capítulo encontra-se dividido em duas seções. Na primeira, são apresentados os principais aspectos da ECT, seus pressupostos e atributos. $\mathrm{Na}$ seqüência faz-se um breve histórico do pregão eletrônico, destacando sua evolução, aplicabilidade, fases e estrutura.

\section{Pressupostos e atributos da economia dos custos de transação}

A ECT é um dos ramos da Nova Economia Institucional (NEI). Segundo Silva e Brito (2013) a NEl surgiu do questionamento à teoria neoclássica quanto aos pressupostos de racionalidade e concorrência perfeita. Além disso, a não consideração das instituições na coordenação dos agentes justificou a adoção desse mainstream. O principal papel das instituições, na NEl, é restringir as ações humanas (AZEVEDO, 2000, p. 35). Nesse sentido, as instituições, segundo North (1991, p. 97), "estruturam a interação política, econômica e social" por meio de regras formais e informais, capazes de reduzir as incertezas nas "trocas".

A NEl trata as instituições em dois níveis analíticos: o nível macro institucional e o micro institucional. O primeiro aborda o ambiente institucional, suas origens e mudanças e atribui às instituições o papel de limitador do comportamento da sociedade. $\mathrm{O}$ segundo trata das estruturas de governança e representa a economia das organizações (AZEVEDO, 2000; ZYLBERSZTAJN, 2005). Williamson refere-se a NEl como um ramo contratual de eficiência, onde a estrutura de governança pode garantir redução nos custos de transação. Neste artigo, o enfoque se dará nos arranjos institucionais, a partir dos pressupostos da ECT. A ECT, que tem Oliver Williamson como principal precursor, surgiu com Coase, a partir da publicação de seu artigo, em 1937, "The nature of the Firm". A preocupação central de Coase (1937) com a firma do mundo real permitiu que se rompesse um paradigma de que o mercado funcionava a custo zero. $\mathrm{O}$ autor identificou os custos associados à realização das transações, e propôs que novas formas de transacionar, além do mercado, poderiam ser utilizadas. Para Saes (2008, p. 32) o autor argumentou que "a firma é uma relação orgânica entre agentes, que se efetiva por meio de contratos, sejam explícitos, como os de trabalho, ou implícitos, como parcerias formais". Segundo Williamson (1985, p.14, tradução nossa) "a firma como função produção foi suplantada (ou ampliada) pelo conceito de firma como estrutura de governança".

O pressuposto básico da ECT é a existência dos custos de transação. Williamson (1985) distingue os custos de transação, como ex-ante e ex-post à contratação. O primeiro se relaciona aos custos de "redigir, negociar e salvaguardar um acordo", o segundo surge ex-post à contratação e está relacionado principalmente a incompletude contratual e a consequente necessidade de monitoração do contrato. Saes (2008, p.32) descreve da seguinte forma: "os custos de transação são custos de trocar, capturar e proteger direitos de propriedade".

$\mathrm{Na}$ ECT esses custos estão relacionados a dois pressupostos comportamentais: a racionalidade limitada e o oportunismo. Segundo Williamson (1985) a racionalidade se refere aos limites da competência cognitiva humana. $\mathrm{O}$ autor distingue três níveis de racionalidade: a forma forte, que contempla a maximização; a semiforte ou racionalidade limitada, abordada pela ECT; e a forma 
fraca ou racionalidade orgânica.

A impossibilidade de se antecipar a todas as contingências de uma contratação está relacionada à racionalidade limitada do indivíduo. Para Williamson (1993), citado por Martins e Souza (2014), essa limitação cognitiva se estende ao recebimento, recuperação e processamento de informações. Para Zylbersztajn (2000, p. 33) "a limitação decorre da complexidade do ambiente que cerca a decisão dos agentes, que não conseguem atingir racionalidade plena". De forma geral, dessa limitação decorre a incompletude natural dos contratos, emergindo lacunas que dão margem a ações oportunistas pelos agentes.

O oportunismo segundo Williamson $(1985$, p. 47) refere-se ao auto-interesse com avidez dos indivíduos. Esse comportamento se manifesta tanto em formas mais evidentes como mentir, roubar e trapacear, quanto em formas mais sutis, porém, não menos prejudiciais, geralmente atreladas à revelação incompleta da informação, numa tentativa dos agentes em enganar, distorcer e disfarçar, ou outras maneiras de confundir. É o oportunismo, o responsável por condições de assimetria de informação, reais ou inventadas, e fonte problemática de incerteza comportamental nas transações econômicas (WILLIAMSON, 1985, p. 47-48).

Diante da evidência da racionalidade limitada e do comportamento oportunista, os agentes constroem estruturas de governança. Para evitar prejuízos decorrentes do oportunismo, os agentes se valem de coleta de informações, salvaguardas contratuais e utilização do sistema jurídico, o que inevitavelmente aumentam os custos da transação (AZEVEDO, 2000).

Além do aspecto comportamental, como já visto, na ECT os atributos que diferenciam as transações ao mesmo tempo em que norteiam as tomadas de decisões nas contratações, são: a frequência, a especificidade dos ativos e a incerteza. A frequência está relacionada com a recorrência com que uma transação se efetiva. Quanto maior a frequência, menores os custos ex-ante na elaboração de contratos, bem como menor a probabilidade de comportamento oportunista, devido à reputação adquirida entre os agentes (AZEVEDO, 2000).

A especificidade de ativos está relacionada ao grau de investimentos específicos realizados pela firma (WILLIAMSON, 1985). Quanto maior os investimentos, maiores as perdas associadas a uma ação oportunista por parte do outro agente e maiores os custos de transação (AZEVEDO, 2000). Já a incerteza, segundo Martins e Souza (2014, p. 74) "refere-se às mudanças no ambiente econômico que impossibilita avaliações precisas sobre determinadas ações". Para Saes (2008, p.33) quanto maior a incerteza, mais complexo torna-se o desenvolvimento de parcerias de longo prazo, menor a probabilidade de conhecer eventos futuros e maior a possibilidade de comportamento oportunista.

Williamson (1985) distingue três tipos de incerteza: primária, secundária e comportamental. A primária tem relação com as contingências ambientais, surgem de atos aleatórios da natureza ou mudanças imprevisíveis na preferência dos consumidores. A secundária surge da falta de informação quanto às decisões e planos dos concorrentes. A comportamental é um tipo estratégico de incerteza atribuída ao oportunismo. São eventos únicos advindos de problemas das ações humanas. Silva e Brito (2013, p. 182) citando Frank Knight (2002, p. 224) distinguem o risco da incerteza afirmando que a última "não possui bases válidas ou experiência passada para determinar a probabilidade de uma ocorrência específica". 
Do alinhamento dos pressupostos comportamentais com os atributos da transação são determinadas as estruturas de governança. As estruturas tratadas por Williamson são mercado, integração vertical e formas hibridas. Martins e Souza (2014) baseados na proposta de Williamson (1985) explicam que nas relações contratuais, dada a incompletude dos contratos pela racionalidade limitada, os agentes estão expostos ao comportamento oportunista. $O$ não alinhamento entre os atributos da transação e as estruturas de governança, gera custos de transação, tornando relações de troca menos eficientes (WILLIAMSON, 1985).

\section{Pregão eletrônico - breve histórico}

As relações de troca nos órgãos públicos acontecem por meio de licitação conforme estabelecido no artigo 37, XXI da Constituição Federal (CF) de 1988, regulamentado pela Lei 8.666/93. A licitação pode ser definida como "o conjunto de procedimentos [...] através do qual a Administração cria meios de verificar, entre os interessados habilitados, quem oferece melhores condições para a realização de obras, serviços [...]" (PISCITELLI, 2008, p.234).

As modalidades de licitação estabelecidas pela Lei no 8.666/93 são: concorrência; tomada de preços; convite; concurso; e leilão. A sexta modalidade, o Pregão, teve sua origem marcada pela Lei no 9.472/97, no âmbito da Anatel. A experiência foi tão vantajosa que sua utilização passou a ser autorizada, na esfera federal, por meio da Medida Provisória no 2.026/00, sucedida pela Medida Provisória no 2.182-18/01, que fora regulamentada pelo decreto no 3.555/00. 0 Decreto no 3.555/00 foi alterado pelos decretos no 3.693/00 e no 3.784/01. Em meio a isso, o Decreto no 3.697/00 instituiu o PE. Só em 17 de julho de 2002, que a Medida Provisória no 2.182-18/01 foi convertida na Lei Federal no 10.520 que instituiu a nova modalidade de licitação (NIEBUHR, 2015; FURTADO, 2015).

O Pregão trouxe inovações para as aquisições públicas. Com critério de julgamento único, o menor preço, o PE é destinado somente à aquisição de bens e serviços comuns, definidos pela Lei $n^{\circ}$ 10.520/02 "como aqueles cujos padrões de desempenho e qualidade possam ser objetivamente definidos pelo edital, por meio de especificações usuais no mercado".

Características que diferenciam o pregão das demais modalidades estabelecidas na Lei no 8.666/93 são apresentadas por Niebuhr (2015). Quanto às fases da licitação, de habilitação e julgamento de propostas, há uma inversão no pregão, primeiro são julgadas as propostas e só depois a habilitação, apenas das propostas que apresentarem os melhores preços, imprimindo celeridade ao processo. Outra característica é que no pregão, os licitantes têm oportunidade de reduzir seus preços sucessivamente até que se esgotem os lances no PP ou o tempo no PE.

$\mathrm{Na}$ forma eletrônica praticamente todos os procedimentos do pregão acontecem por meio da internet. Atualmente o PE é regulamentado pelo decreto no 5.450/2005, que determina sua obrigatoriedade. No âmbito federal o pregão eletrônico acontece por intermédio do sistema eletrônico do Ministério do Planejamento, Orçamento e Gestão, o Comprasnet SIASG. De acordo com o Portal de Compras do Governo Federal (2017), o Sistema Integrado de Administração de Serviços Gerais - SIASG, é o sistema informatizado de apoio às atividades operacionais do Sistema de Serviços Gerais - SISG. Segundo Inamine, Erdmann e 
Marchi (2012, p.12-13) "o sistema eletrônico de compras do governo federal consiste em uma ferramenta de gestão criada para aproveitar toda a potencialidade da tecnologia da informação e comunicação nas compras públicas".

Para Piscitelli (2008, p.245) toda licitação deve "desenvolver-se em uma sequência lógica a partir da existência de uma necessidade a ser atendida". Duas fases principais podem ser diferenciadas no PE, a fase interna ou preparatória e a fase externa ou executória. A fase interna é regulamentada pelo art. 9 do decreto no 5.450/05. Nessa fase são elaborados o termo de referência e o edital e são designados o pregoeiro e sua equipe de apoio, sendo o primeiro responsável pela condução do pregão conforme atribuições do art.11 do Decreto no 5450/05.

A fase externa ou executória se inicia com a publicação do instrumento convocatório nos termos do art.17 do Decreto no 5450/05. O Comprasnet é responsável pela viabilização da fase externa do PE. O detalhamento da fase executória do pregão é definido a partir do artigo no 21 do mesmo Decreto. A fase externa do PE acontece respeitando uma sequência de ações, incluindo: a etapa convocatória, o julgamento, a habilitação, a adjudicação, a homologação, e, por fim, a contratação. Para Piscitelli $(2008$, p.255) o PE permite que "a sociedade tome conhecimento, em tempo real" de todo processo de aquisição ou contratação, desde os lances até a homologação do objeto.

\section{METODOLOGIA}

Para realização deste trabalho foi utilizada a metodologia qualitativa, a qual, segundo Godoy (1995, p. 58) envolve a "[...] obtenção de dados descritivos sobre pessoas, lugares e processos interativos pelo contato direto do pesquisador com a situação estudada, procurando compreender os fenômenos segundo a perspectiva dos sujeitos, ou seja, dos participantes da situação em estudo".

$\mathrm{O}$ tipo de pesquisa foi a pesquisa descritiva. Este tipo de pesquisa, conforme Barros e Lehfeld (1986, p. 90), é definida como aquela em que ocorre a observação, o registro, a análise, e a correlação dos fatos ou fenômenos sem manipulação de variáveis pelo pesquisador. A pesquisa envolveu a pesquisa documental, bibliográfica e a pesquisa de campo, entendida como a coleta de dados no local do surgimento do fenômeno. No primeiro momento buscou-se fazer um levantamento bibliográfico sobre o tema e, posteriormente, levantou-se dados secundários para complementar os dados primários obtidos.

A pesquisa foi realizada em uma Instituição Pública Federal, localizada no estado do Paraná, onde todas as contratações são realizadas de acordo com a legislação já apresentada. Optou-se pela instituição, pois a principal modalidade de licitação utilizada para as contratações é o PE, objeto de análise nesse estudo. Para levantamento dos dados primários, foram utilizados entrevista semi-estruturada e observação sistemática não participante.

A observação segundo Lakatos e Marconi (2011, p. 277) "tem como principal objetivo registrar e acumular informações. Deve ser controlada e sistemática". No caso da observação não participante, o pesquisador entra em contato com a realidade estudada, porém não se integra a ela, ou seja, possibilita um contato do investigador, como espectador, com o fenômeno pesquisado. (LAKATOS e MARCONI, 2011, p. 278). Por meio da observação foi possível acompanhar e 
registrar as fases, interna e externa, de um processo de aquisição de materiais de consumo, por meio do PE. Esse acompanhamento permitiu conduzir as entrevistas pessoalmente ou respondidas por e-mail, seguindo as fases do processo licitatório, possibilitando melhor compreensão das informações dos respondentes.

Foram ouvidos dois pregoeiros e seis requisitantes da Instituição, observandose a obtenção de convergência nas falas. Os pregoeiros foram selecionados por disponibilidade e seu tempo de atuação no departamento de compras, com preferência para àqueles com pelo menos 12 meses de experiência com a modalidade PE. Quanto aos requisitantes, o roteiro de questões foi encaminhado àqueles que acompanham os processos de $\mathrm{PE}$, nas fases interna e externa, quando assumem o papel de fiscais. Além disso, se deu preferência àqueles que participam tanto na aquisição de materiais quanto na contratação de serviços. Os requisitantes escolhidos participaram de aproximadamente $70 \%$ das aquisições realizadas pela Instituição em 2016.

As entrevistas pessoais com os pregoeiros, e a resposta ao roteiro de questões para os requisitantes, por e-mail, ocorreram nos meses de junho e julho de 2017. Cada entrevista teve duração de aproximadamente 50 minutos e foi realizada pelo próprio pesquisador. Os roteiros foram enviados por e-mail para os requisitantes previamente selecionados, após orientações presenciais, que retornaram suas respostas, em média, após dois dias. A análise das informações obtidas foi realizada sob enfoque da análise de conteúdo, a qual é definida por Rocha e Deusdará (2005, p 308) como um "conjunto de técnicas de análise das comunicações que aposta grandemente no rigor do método como forma de não se perder na heterogeneidade de seu objeto". Segundo os autores, o que se procura é demonstrar o propósito das mensagens, pelo esclarecimento de elementos de significações.

A Análise de Conteúdo foi complementada pela análise de discurso, buscando interpretar a fala dos entrevistados e entender suas motivações, ou seja, "compreender os sentidos que o sujeito manifesta através do seu discurso" (CAREGNATO; MUTTI, 2006, p.684). Assim, as informações foram agrupadas e analisadas segundo a fala dos entrevistados, e comparadas à teoria básica apresentada.

\section{APRESENTAÇÃO E ANÁLISE DOS RESULTADOS}

$\mathrm{Na}$ busca pela identificação das incertezas que influenciam as contratações públicas realizadas por intermédio do $\mathrm{PE}$, foram ouvidos pregoeiros e requisitantes da Instituição. A principal modalidade, O PE, foi utilizada em 26 processos de aquisição em 2016. Dos processos finalizados, 19 resultaram em aquisições de materiais, 05 em contratações de serviços, e 02 resultaram desertos, ou seja, não ocorreram propostas de empresas para à aquisição pretendida. Através da observação foi possível compreender melhor as incertezas que permeiam cada etapa da contratação. Assim, os resultados e discussões serão apresentados respeitando as fases obrigatórias do $\mathrm{PE}$.

$\mathrm{Na}$ fase interna ou preparatória do PE, determinados pelo art. 9ㅇ do decreto no 5.450/05, dois documentos merecem atenção especial, são eles: o termo de referência (TR) e o edital. Segundo Furtado (2015, p. 439) "o termo de referência é da mais alta importância para a realização da sessão pública do pregão". No TR 
deverá, conforme art. 9o $\S 2$ 2 "[...] conter elementos capazes de propiciar avaliação do custo pela administração diante de orçamento detalhado, definição dos métodos, estratégia de suprimento, valor estimado em planilhas de acordo com o preço de mercado [...]". É ele que permitirá ao pregoeiro tomar as decisões acerca da classificação das propostas.

O edital, por sua vez, é onde são estabelecidos critérios de aceitação das propostas bem como as exigências de habilitação, sanções, prazos e condições que sejam consideradas relevantes para a celebração e execução do contrato, e o atendimento das necessidades da administração.

$\mathrm{Na}$ instituição pesquisada, o TR é elaborado pelo requisitante e fornece subsídios para a elaboração do edital, pelo pregoeiro. Os dois atores são fundamentais para o sucesso dessa etapa do processo. Os requisitantes descreveram como principais funções nesta etapa: o levantamento das necessidades; elaboração do TR; pesquisa de preço de mercado; descrição dos materiais e serviços; e especificação do objeto a ser contratado. Já os pregoeiros são responsáveis por: analisar as pesquisas de preço e descrição dos itens, ambos fornecidos pelo requisitante; auxiliar na confecção do TR; elaborar a minuta do edital e seus anexos; encaminhar os documentos para as autoridades competentes; e publicar o edital.

Requisitantes e pregoeiros demonstraram dificuldades em dois momentos durante a fase interna: na descrição dos produtos e serviços, e na obtenção e elaboração dos orçamentos. A falta de conhecimento técnico para descrever adequadamente $\mathrm{o}$ produto a ser contratado foi relatada unanimemente pelos requisitantes. Segundo eles, a incerteza quanto à descrição estar adequada, aumenta em contratações não frequentes, pois prever todas as contingências se torna impossível e pode permitir falhas como "aquisição de produto de baixa qualidade". Essa situação, que define uma condição de racionalidade limitada, ao se considerar a proposição de Williamson (1985), estabelece uma condição de incerteza quanto aos resultados a serem alcançados, dado que se estabelecem condições para comportamento oportunista.

Para os pregoeiros, a impossibilidade de inferir se a descrição do material ou serviço fornecida pelo requisitante é a melhor para a futura contratação, se está incompleta ou ainda direcionada para determinada marca, são as incertezas iniciais. Dito de outra forma, condições de racionalidade limitada e condições de seleção adversa, definem as condições de incerteza para o processo, em um contexto ex-ante.

Com relação à pesquisa de preço, a maior dificuldade apontada é identificar se o valor orçado reflete a realidade do mercado. Nesse caso, considera-se que condições de seleção adversa tratadas por Williamson (1985) permitem, em complemento, que casos de oportunismo também possam ocorrer. Na percepção dos pregoeiros, a não obtenção de preços reais do mercado se deve ao fato de que em orçamentos para administração pública os fornecedores tendem a elevar os preços, buscando aumentar ganhos durante a sessão pública. Outra situação relatada é o "preço orçado não ser o do material requisitado", ou seja, diferente do material descrito no TR. Assim, os valores orçados acima ou abaixo do preço real do mercado são fontes de incertezas. Se estiver acima, é possível que a instituição pague um preço alto por um produto de baixa qualidade. Se estiver abaixo, resultam em itens ou processos inteiros desertos. Essas incertezas influenciam na 
implementação do processo de PE, gerando retrabalho, perda de tempo, aumento dos custos e do processo.

A fase externa ou executória do PE se inicia com a publicação do instrumento convocatório. Resumidamente, a fase externa inclui o encaminhamento da proposta pelo fornecedor por meio do Comprasnet; abertura da sessão pública; análise preliminar das propostas; fase competitiva ou de lances; fase de análise e aceitação da proposta; fase de habilitação; fase de manifestação de intenção de recurso; adjudicação e homologação. Por fim, o adjudicatário é convocado para assinar o contrato ou a ata de registro de preços no prazo definido no edital (DECRETO № 5.450/05; FURTADO, 2015, p. 448-449).

$\mathrm{Na}$ instituição, verificou-se que os requisitantes são responsáveis por auxiliar o pregoeiro, durante a fase de análise e aceitação da proposta, na avaliação dos produtos ofertados pelos licitantes. Demais atribuições como recebimento do material, fiscalização e acompanhamento dos contratos de serviço e ateste de notas ocorrem após a contratação. Já os pregoeiros são responsáveis pela condução do processo, nos termos do Decreto no 5.450/05.

Para os pregoeiros, na fase externa, a tomada de decisão é permeada de muita incerteza. Essa incerteza se deve, segundo eles, a vários fatores, dentre eles: a possibilidade de problemas na fase interna que serão refletidos na fase externa; falta de experiência; falta de capacitação para atuar na área de compras; falta de previsão legal para contingências do processo; comportamento impróprio do fornecedor. Assim, problemas de racionalidade limitada ex-ante e comportamento oportunista ex-post são responsáveis pela condição de incerteza para essa fase, mesmo diante de compras de produtos padronizadas.

Por vezes, as incertezas da fase interna, quanto à descrição incompleta, excessiva ou direcionada, ou valores de referência equivocados, se materializam, logo após a publicação do edital, em pedidos de esclarecimento e impugnações. Esses pedidos podem resultar, após análise do pregoeiro, em: suspensão do processo, alteração no TR, republicação do edital, nova contagem de prazos para a sessão pública ou ainda cancelamento de todo o processo para revisão e futura publicação. A tentativa de transformação na relação para uma condição de menor incerteza a partir do maior detalhamento da contratação é limitada pelos aspectos inerentes ao ambiente institucional, notadamente pelo regramento formal.

A maior delimitação (busca de contrato completo), estabelece rigidez para a relação entre comprador e possível fornecedor, por outro lado, essa rigidez se limita a aspectos básicos dos pedidos, dado que uma especificação mais detalhada pode significar limites à concorrência, podendo prejudicar ou frustrar o processo. Porém, muitas vezes a incerteza quanto à descrição se materializa apenas na fase de análise e aceitação da proposta do produto ou serviço. Nessa fase, pregoeiros e requisitantes apontam a recorrência dos mesmos problemas. Segundo um dos entrevistados a descrição abrangente gera "oportunidade para o licitante se beneficiar dessa lacuna, ofertando um material que objetivamente atende a descrição, porém, é notório que aquele material é pouco durável, pouco eficiente [...]". Ou seja, é possível no PE, a aceitação de produto com qualidade inferior a desejada, porém que atende ao que foi solicitado no TR.

Assim, a incerteza ex-post se concretiza na possibilidade do moral hazard (ação escondida) em face da possiblidade de, a partir da limitação quanto à possiblidade de se apresentar condicionantes, abrir espaço para que o comportamento 
oportunista ocorra. Nesse aspecto a relação contratual não é capaz de exercer controle sobre o processo, bem como de estabelecer salvaguardas. Nesse caso, além da incerteza quanto à qualidade, enfrenta-se a incerteza de preço acima do mercado para o nível de qualidade esperada.

Essa prática pode ser evidenciada em outra fala dos entrevistados. Segundo eles, a maioria dos fornecedores "copia e colam os parâmetros mínimos do termo de referência, não colocando a descrição exata do produto ou serviço ofertado", isso dificulta a desclassificação da proposta, visto que, os fornecedores estão se comprometendo a entregar exatamente o descrito no TR. Esse comportamento dos fornecedores gera nos entrevistados expectativa de entrega de materiais de baixa qualidade, devido, segundo um deles "à malícia dos fornecedores na interpretação da descrição dos produtos". A "malícia" relatada pelos entrevistados pode ser explicada pela assimetria de informação entre estes fornecedores e os servidores da instituição. Segundo Faria, Ferreira e Gonçalves (2013) essa assimetria se deve ao fato do fornecedor ter, além do conhecimento da legislação e de suas possíveis brechas, um conhecimento técnico do produto ofertado maior que o da instituição ao descrevê-lo no TR. Dessa maneira, se de um lado incertezas quanto à descrição abrangente ou incompleta, e preços divergentes do mercado, podem estar associados à racionalidade limitada e leva tanto a incerteza ao design do contrato quanto ao atendimento do interesse do comprador (WILLIAMSON, 1985). Por outro lado, incertezas quanto à descrição altamente detalhada do produto ou serviço, que pode ocasionar um direcionamento de marca, é proibida pela lei, ou seja, o próprio regramento formal pode levar a ineficiência na contratação.

A identificação dessa incapacidade de, ex-ante, a instituição definir as regras do jogo, por meio de descrições completas e se valendo de salvaguardas contratuais, gera incerteza quanto ao resultado da aquisição e como consequência à incerteza do próprio PE. A racionalidade limitada ao impossibilitar a antecipação de todas as situações futuras expõe as transações ao comportamento oportunista. Explicitamente identificado na fase de aceitação da proposta, conforme relatado anteriormente, quando o fornecedor utiliza, de formas definidas por Willianson (1985) como sutis desse comportamento, a fim de distorcer, disfarçar ou outras formas de confundir o pregoeiro e o requisitante no momento da aceitação da proposta. O comportamento oportunista também foi identificado após a contratação. Nessa etapa, os entrevistados relatam comportamento "desleal" por parte de alguns fornecedores, como: envio de produtos com qualidade inferior ao aceito durante o PE; solicitação de troca de marca, pois o valor adjudicado muitas vezes é inferior ao produto ofertado; entrega parcial de produtos; entrega de produtos obsoletos, ruptura do contrato, entre outros. Pela fala dos entrevistados o comportamento oportunista dos fornecedores é resultado de incertezas advindas da incompletude da legislação, da racionalidade limitada ao descrever os produtos e serviços e da assimetria de informação entre estes e os fornecedores. Essas incertezas fazem com que o pregoeiro e o requisitante tenham que, por vezes, "aceitar produtos mesmo que não satisfaça totalmente a necessidade que provocou a aquisição".

Reforçando a afirmação de Zylbersztajn (2000, p. 31) de que o oportunismo implica em reconhecer que os agentes podem se valer de informações privilegiadas, rompendo contratos e "em última análise, feriando códigos de ética tradicionalmente aceitos pela sociedade". Além disso, os resultados reforçam a 
afirmação de Oura et al. (2012) de que o PE não é suficiente para coibir as ações oportunistas, mesmo com aumento da transparência do processo. Esse resultado corrobora ainda com a afirmação de Faria, Ferreira e Gonçalves (2013), de que, diante da incompletude das descrições, a maioria das instituições, por eles analisadas, agem com oportunismo, buscando obter ganhos mais elevados, fazendo uso de condutas antiéticas.

Ainda que os contratos prevejam punições, multas e sanções, ao licitante que não cumpre o contratado, pouco se refere à qualidade do produto ofertado e entregue pelo fornecedor. Por meio da fala dos entrevistados, percebe-se que a qualidade do produto a ser entregue é a maior incerteza da contratação. $O$ que reforça a conclusão de Niebuhr (2015), ao afirmar que, quando isolamos a variável qualidade dos produtos e serviços oferecidos à Administração, o PE não trouxe novidades para as contratações públicas. Ainda segundo o autor, dado seu objetivo de agilizar o processo de compras, essa modalidade pode até agravar essa dificuldade.

Para obter qualidade, além do preço, único critério de julgamento do $P E$, outras variáveis precisam ser consideradas para aceitação da proposta. Embora os editais analisados exijam atestado de capacidade técnica e por vezes amostra de produtos, os relatos dos entrevistados demonstram dificuldade em desclassificar fornecedores que apresentam o menor preço e "copiam e colam" a descrição do TR. Segundo eles, é preciso encontrar formas, principalmente durante o planejamento da fase interna, para inibir a entrega de produtos e serviços de baixa qualidade. Isso, entretanto, depende da revisão no regramento formal.

Outro fator determinante de incerteza está relacionado ao atributo da transação, identificado por Williamson (1985) como frequência. Não existe frequência nas contratações, por intermédio do $P E$, assim a confiança entre a instituição e o fornecedor é muito baixa. Salvo contratos continuados; mesmo nos processos que se repetem ano a ano como aquisição de materiais de expediente e limpeza, os fornecedores se renovam a cada contratação, não criam vínculos ou reputação. Zylbersztajn $(2000$, p. 31) afirma que a reputação, além das garantias legais e princípios éticos é uma das razões para a continuidade dos contratos. Ao comparar o processo de aquisição de materiais de expediente dos anos de 2016 e $2017,80 \%$ dos fornecedores se renovaram. Assim, a reputação não se desenvolve, o que aumenta a incerteza e a recorrência do comportamento oportunista dos agentes envolvidos nessa transação.

Ainda que, segundo Azevedo (2000), a coleta de informações, salvaguardas contratuais e utilização do sistema jurídico, aumentam os custos da transação. Essas são as ferramentas mais indicadas para a instituição evitar prejuízos decorrentes do oportunismo. Não significa que todos os agentes são ou agem de maneira oportunista todo tempo, mas que esse comportamento faz parte do mudo real e está presente nas contratações realizadas por intermédio do PE na instituição estudada (ZYLBERSZTAJN, 2000).

Segundo os pregoeiros entrevistados, quando comparado às outras modalidades de licitação, o pregão eletrônico representa algumas vantagens. Foram citadas a transparência dos atos do pregoeiro e fornecedores, e o tratamento impessoal e imparcial no julgamento das propostas, garantido pelo distanciamento físico entre pregoeiros e fornecedores. Quanto à celeridade, os entrevistados relataram pontos positivos como a inversão das fases de julgamento 
e habilitação e a utilização do sistema eletrônico que já classifica os lances, diminuindo o trabalho do pregoeiro. Porém, reforçaram que as incertezas do processo, principalmente quanto ao comportamento do fornecedor acabam reduzindo essa celeridade.

Essa afirmação pode ser evidenciada ainda na fase de aceitação. Durante o acompanhamento do processo de aquisição, foi possível notar que, por vezes, os fornecedores que venceram o certame, não enviaram a documentação no prazo estabelecido ou solicitaram desclassificação por ofertar lance, segundo eles inexequível. Outras vezes, enviaram toda documentação online, porém quando convocados não enviaram a documentação original no prazo, fazendo com que o pregoeiro voltasse à fase de convocação de proposta. Embora exista previsão de punições para os licitantes que não cumprem as exigências do edital, as práticas relatadas reduzem a celeridade do $\mathrm{PE}$, aumentam a incerteza e geram custos para a Administração.

Para minimizar as dificuldades e incertezas durante o PE, os pregoeiros sugeriram que a elaboração do $T R$, incluindo a descrição do produto ou serviço, deveria ficar a cargo de uma comissão de especialistas, incluindo o requisitante e o pregoeiro. A atenção ao TR se deve ao fato de este ser o único instrumento de ligação entre a necessidade (descrição do material ou serviço) da instituição e o fornecedor. Outra sugestão diz respeito à maior capacitação sobre a legislação para pregoeiros e requisitantes.

\section{CONSIDERAÇÕES FINAIS}

O objetivo desse trabalho foi identificar as incertezas nas contratações públicas realizadas por intermédio do pregão eletrônico em uma instituição pública federal, localizada no estado do Paraná. Observou-se que apesar dos benefícios do pregão eletrônico, a incerteza comportamental, abordada pela ECT, nessa modalidade de licitação é explicita.

A pesquisa evidenciou que as incertezas estão presentes em todo o processo do PE e são decorrentes dos pressupostos comportamentais discutidos pela ECT. Por um lado, tem-se a incerteza decorrente da racionalidade limitada dos requisitantes e pregoeiros em prever todas as características do objeto a ser licitado, a incompletude contratual e da legislação. Do outro lado, dada à racionalidade limitada, tem-se o comportamento oportunista por parte de alguns licitantes ao se aproveitar das lacunas contratuais e da assimetria de informação para entregar produtos diferentes do solicitado ou com qualidade inferior ao demandado pela contratante.

Assim, percebe-se que essas incertezas influenciam diretamente na qualidade e no valor dos produtos e serviços adquiridos; no aumento dos custos de transação; na redução da celeridade e consequentemente na redução da eficiência das aquisições por intermédio do PE.

Evidências da pesquisa associadas à teoria base apresentada permite concluir que as contratações por intermédio do PE geram custos de transação ex-ante e expost. Ex-ante para prever, redigir e salvaguardar o acordo. Ex-post para monitorar e fazer valer seu direito.

Os resultados demonstram ainda que a maior incerteza, geradora da 
ineficiência nas contratações por PE da instituição, está na descrição incompleta, direcionada ou abrangente demais. Dessa forma, uma revisão dos métodos utilizados na descrição dos produtos e serviços a serem contratados por intermédio do PE e capacitações e ações conjuntas, entre pregoeiros e requisitantes, podem representar um recurso estratégico para redução das incertezas do PE oriundas da assimetria de informações entre estes e os fornecedores.

Mesmo os resultados empíricos deste artigo apresentando algumas limitações, acredita-se que o presente trabalho se mostrou relevante, pois ao identificar as incertezas da contratação por intermédio do $\mathrm{PE}$, a instituição poderá buscar ferramentas para minimizar seus efeitos.

Por fim, sugere-se a replicação dessa pesquisa em outras instituições e a inclusão da percepção de outros atores como fornecedores e órgãos de controle e fiscalização internos e externos, para complementar e permitir uma visão mais precisa da ineficiência das contratações, pela incerteza, por intermédio do PE. Além disso, uma análise da recorrência das incertezas identificadas na pesquisa permitirá traçar um perfil do comportamento dos fornecedores e desenvolver mecanismos para minimizar o impacto da racionalidade limitada e do comportamento oportunista nas contratações por intermédio do PE. 


\title{
Influence of uncertainties on public procurement through electronic tranding
}

\begin{abstract}
Despite the significant changes brought about by electronic trading, studies demonstrate the recurrence of problems with hiring through the tool, generating uncertainty and costs in public contracting. In this article, the objective was to identify the uncertainties in the public procurement made through the electronic trading session. Based on the theoretical approach of the Economics of Transaction Costs. Data collection involved documentary, bibliographic research and field research at a Federal Public Institution of Paraná. The analysis of the information obtained was carried out under the content analysis approach, complemented by discourse analysis. The research evidenced the presence of the behavioral uncertainty discussed by the presented basic theory. This uncertainty is the result of the limited rationality of preachers and solicitors and opportunistic behavior of suppliers. The evidence of the research associated with the base theory allowed to conclude that the hirings through the electronic trading generate ex-ante and ex-post transaction costs for the studied institution. Thus, the review of the methods used in the description of products and services and capabilities can mean ways to reduce the uncertainties of electronic trading and obtain greater efficiency for the analyzed institution.
\end{abstract}

KEY WORDS: Public procurement. Opportunism. Limited Rationality. 


\section{REFERÊNCIAS}

AZEVEDO, P. F. de. Nova Economia Institucional: referencial geral e aplicações para a agricultura. Agriculturaem São Paulo, São Paulo, v. 47, n. 1, p. 33-52, 2000.

BARROS, A. J.; LEHFELD, N. A. Fundamentos de metodologia. São Paulo: McGraw-Hill, 1986.

BRASIL. Constituição da República Federativa do Brasil. Brasília, 1988.

Lei no 8.666 - "Regulamenta o art. 37, inciso XXI, da Constituição Federal, institui normas para licitações e contratos da Administração Pública e dá outras providências". Data da legislação: 21/06/1993 - Publicação DOU: 22/06/1993. Brasília, 1993.

Lei no 10.520 -"Institui, no âmbito da União, Estados, Distrito Federal e Municípios, nos termos do art. 37, inciso XXI, da Constituição Federal, modalidade de licitação denominada pregão, para aquisição de bens e serviços comuns, e dá outras providências". Data da legislação: 17/07/2002 - Publicação DOU: 18/07/2002. Brasília, 2002.

Decreto no 5.450 - "Regulamenta o pregão, na forma eletrônica, para aquisição de bens e serviços comuns, e dá outras providências". Data da legislação: 31/05/2005- Publicação DOU: 01/06/2005. Brasília, 2006.

CAREgNATO, R. C. A.; MUTTI, R. Pesquisa Qualitativa: Análise De Discurso Versus Análise De Conteúdo. Texto Contexto Enferm, Florianópolis, v. 15, n. 4, p. 67984, 2006.

COASE, R. H. The Nature of the Firm.Economica, New Series, v. 4, n. 16. p. 386405.nov., 1937.

FARIA, E. R. de; FERREIRA, M. A. M.; GONÇALVES, M. A. Avaliação dos Riscos do Pregão Eletrônico: uma abordagem pela Teoria da Nova Economia Institucional. Revista de Ciências da Administração, Florianópolis, v. 1, n. 1, p.211-227, 10 dez. 2013.

FURTADO, L. R. Curso de licitação e contratos administrativos. 6. ed. rev. atual. e ampl. Belo Horizonte: Fórum, 2015. 815 p. 
INAMINE, R.; ERDMANN, R. H; MARCHI, J. J. Análise do sistema eletrônico de compras do governo federal brasileiro sob a perspectiva da criação de valor público. Revista de Administração da USP, São Paulo, v. 47, n. 1, p. 124-139. Jan./Mar. 2012.

LAKATOS, E. M.; MARCONI, M. de A. Metodologia Científica. 6. ed. São Paulo: Atlas, 2011.

MARTINS, D. L. C. C.; SOUZA, J. P. de. Atributos da transação e mensuração, e sua influência nas relações entre cooperados e cooperativas em sistemas agroindustriais suinícolas. Revista de Administração do Mackenzie, São Paulo, v. 15, n. 3, p.69-100, maio/jun. 2014. Edição Especial.

MENEZES, R. A.; SILVA, R. B. da; LINHARES, A. Leilões eletrônicos reversos multiatributo: uma abordagem de decisão multicritério aplicada às compras públicas brasileiras. Revista de Administração Contemporânea, [s.I.], v. 11, n. 3, p.11-33, set. 2007. DOI: http://dx.doi.org/10. 1590/s1415-65552007000300002.

NIEBUHR, J. de M. Pregão Presencial e Eletrônico. 7. ed. Belo Horizonte: Fórum, 2015.

NORTH, D. C. Institutions. The Journal of Economic Perspectives, Vol. 5, No. 1, p. 97-112, 1991.

OURA, M. M. et al. O pregão eletrônico como instrumento de controle de oportunismos no processo licitatório público. Revista de Gestão e Projetos - GEP, São Paulo, v. 3, n. 2, p 260-281, mai./ago. 2012.

PAINEL de Compras do Governo Federal. 2017. Disponível em: <http://www.comprasgovernamentais.gov.br/index.php/painel-de-compras-degoverno>. Acesso em: 01 jun. 2017.

PISCITELLI, R. B. Contabilidade Pública: uma abordagem da administração financeira pública. 9. ed. rev., atualizada até janeiro de 2006. São Paulo: Atlas, 2008.

PORTAL de Compras do Governo Federal. 2017. Disponível em:< http://www.comprasgovernamentais.gov.br/ index.php/comprasnet-siasg>. Acesso em: 15 jun. 2017. p.305-322, 2005. 
SAES, M. S. M. Diferenciação e apropriação da quase-renda na agricultura: a cafeicultura de pequena escala. São Paulo, 2008. 162 f. Tese (Livre Docência) Departamento de Administração, Faculdade de Economia, Administração e Contabilidade, Universidade de São Paulo, São Paulo, 2008.

SILVA, A. A.; BRITO, E. P. Z. Incerteza, racionalidade limitada e comportamento oportunista: um estudo na indústria brasileira. Revista de Administração do Mackenzie, São Paulo, v. 14, n. 1, p. 176-201, jan./fev. 2013.

WILLIAMSON, O. E. The economic institutions of capitalism. New York: Free Press, 1985.

ZYLBERSZTAJN, D. Economia das organizações. p. 23-38. In: ZYLBERSZTAJN, D. ; NEVES, M.F. (Org). Economia e Gestão de Negócios Agroalimentares. São Paulo: Pioneira, 2000.

Recebido: 21 out. 2017.

Aprovado: $01 \mathrm{dez} .2017$

DOI: $10.3895 /$ rbpd.v7n1.7127

Como citar: PADILHA, A.; ARAÚJO, E. C.; SOUZA, J. P. Influência das incertezas nas contratações públicas por intermédio do pregão eletrônico. R. bras. Planej. Desenv.,Curitiba, v. 7, n. 1, p. 67-84, jan./abr. 2018. Disponível em: <https://periodicos.utfpr.edu.br/rbpd>. Acesso em: XXX. Correspondência:

Angélica Padilha

R. Marcílio Dias, 635 - Jardim Paraiso, Apucarana - PR

Direito autoral: Este artigo está licenciado sob os termos da Licença CreativeCommons-Atribuição 4.0 Internacional. 